$12-7-2017$

\title{
Gödel's Incompleteness Theorem
}

\author{
Emma Buntrock \\ University of North Dakota
}

How does access to this work benefit you? Let us know!

Follow this and additional works at: https://commons.und.edu/es-showcase

Part of the Mathematics Commons

\section{Recommended Citation}

Buntrock, Emma, "Gödel's Incompleteness Theorem" (2017). Essential Studies UNDergraduate Showcase. 1.

https://commons.und.edu/es-showcase/1

This Poster is brought to you for free and open access by the Essential Studies Program at UND Scholarly Commons. It has been accepted for inclusion in Essential Studies UNDergraduate Showcase by an authorized administrator of UND Scholarly Commons. For more information, please contact und.commons@library.und.edu. 


\section{Gödel's Incompleteness Theorem Through Logic}

\section{Emma Buntrock}

Department of Mathematics, University of North Dakota

\section{Objectives}

The goal of my research this semester was to use logic problems to help prove Gödel's incompleteness theorem. I have used this universal theorem to specifically look at the world of logic and how it can be applied in these problems.

Introduction

The incompleteness theorem is based of the idea that in a consistent system there are pieces that can not be proved or disproved, causing for incompleteness. The second part of that idea is that such a system can not prove that itself is consistent, which also makes it incomplete. I will verify theses proofs using a series of logic problems that show how a system is incomplete. It is first important to have the background information on Gödel himself. Gödel was an Austrian mathematician who sought asylum from Nazi rule and ended up at the Institute for Advanced Learning at Princeton. Here he was surrounded by other mathematicians, researchers, and discoverers. He was in a great position to work on theorems of his own. While at Princeton, there were many mathematicians working together to come up with the "Theory of Everything", the goal of this theorem was to be able to make mathematicians air tight, complete, and have a way to prove everything in the math field. Gödel did not agree with this idea and began to work on his own theorem that opposed the "Theory of Everything". In 1931 Gödel released his Incompleteness Theorem. His theorem was the opposite of what other mathematicians wanted, but it was very influential to realize there is no perfectly complete formal systems.

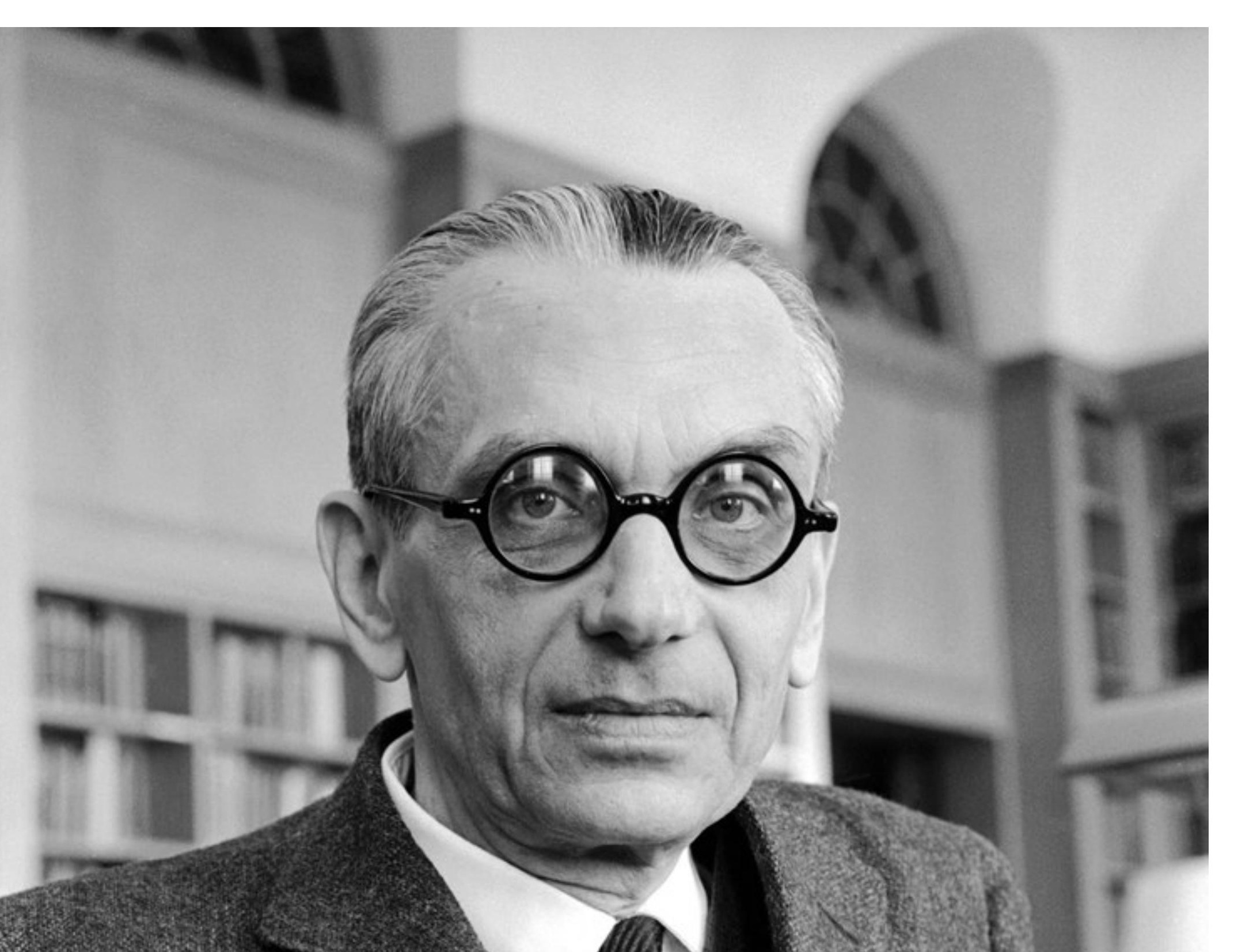

\section{Conclusion}

\section{Example 1}

Example 2

Suppose I offer to give you one of three prizes-Prize A, Prize B, or Prize C. Prize A is the best of the three, Prize $\mathrm{B}$ is middling, and Prize $\mathrm{C}$ is the booby prize. You are to make a statement; if the statement is true, then I promise to award you either Prize A or Prize B, but if your statement is false then you get Prize C-the booby prize. You wish to confound me by making me break my promise.

What statement will do this?

\section{Results}

If you say, "I will get prize C." you will force me to break my promise. This statement works because if I give you prize $\mathrm{C}$, your statement is then true and you should of received Prize A or B based on my requirements. If I give you Prize A or Prize B, your statement is false and I have now gone against my word and given one of the better prizes to a false statement. This is an easy example to see Gödel's Incompleteness Theorem at work. If you consider this logic problem to be a consistent formal system, where each statement makes up the system, we have found a statement that can not be proven nor disproved which verifies Gödel's theorem. This can not be a complete system.

\section{Important Result}

Using logic problems it is easy to see how you can find pieces of the system that can not be proven, causing for an incomplete formal system. The general idea of this is considering your system to be a box. For it to be a complete and consistent formal system, all items within the box must be proven. Gödel's theorem shows that this can not happen without reaching for something outside of the box, which has now violated the terms of a consistent system. This is an continuous idea such that no matter how far you expand your box you will always need another piece further outside of the box to prove something within the box.
In some town $\mathrm{Y}$, there is a barber who shaved all of and only those inhabitants who did not shave themselves. In other words, given any inhabitant $\mathrm{X}$ who didn't shave himself, the barber was certain to shave him. But the barber never shaved any inhabitant X who shaved himself.

Did the barber shave himself?

\section{Results}

If the barber shaved himself, he would of broken his promise of never shaving someone who shaved themselves. If he doesn't shave himself then he has broken his promise of shaving anyone who did not

This is a paradox. Either way he can not follow the rules of the land. When thinking of this logic problem as a system to be proven, each requirement prove or disprove a statement causing for the system to be incomplete and thus, proving Gödel's theorem once again.
Gödel's theorem was considered the greatest discovery of the century because of how wide of an impact it had. Not only did it effect the world of mathematics, but several other disciplines. An example of this is the effect the theorem had on computer science. At this time people wanted to believe that there could be a complete and concrete program that no matter what was plugged in could create the perfect answer every time. Gödel's theorem showed that this was impossible. There would always be some part that could not be proven to have a complete and consistent formal system. This theorem could be applied in any discipline that wanted this perfect completeness such as philosophy, physics, and many more

\section{Continued Research}

While continuing into researching this topic, I would hope to be able to better apply the ideas of Gödel's numbering to logic problems. This will help to better and more formally see his results.

\section{References}

- Raatikainen, Panu, "Gödel's Incompleteness Theorems", The Stanford Encyclopedia of Philosophy (Spring 2015 Edition), Edward N. Zalta (ed.)

- Smullyan, Raymond M. To Mock a Mockingbird: and Other Logic Puzzles Including an Amazing Adventure in Combinatory Logic. Oxford University Press, 1990.

Contact Information

- Email: emma.buntrock@und.edu

- Phone: +1 (320) 4927717

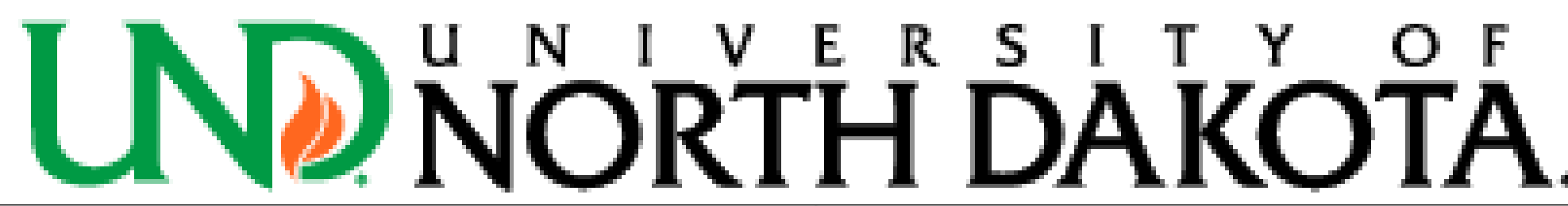
Department of Mathematics 